\title{
TRANSFER OF THE TIBIALIS ANTERIOR TENDON FOR RELAPSED CLUB-FOOT
}

\author{
J. E. Critchley and R. G. Taylor, Oxford, Exgland \\ From the Wingficld-.Morris Orthopacdic Hospital, Oxford
}

In 1923 Dunn adrocated transplantation of the tibialis anterior tendon in selected cases of congenital talipes equinovarus to guard against relapse, but he did not report his results. In 1940 Garceau reported the late results of the operation in forty-four patients (fifty-six feet). In 1947 Garceau and Manning made a study of the results in eighty-six patients and in 110 feet. They reported good results in $\mathbf{8 2 \cdot 7}$ per cent of this series.

Whatever may be the initial cause of congenital talipes equinovarus, muscle imbalance is an important factor in the maintenance of the deformity once relapse has occurred. When deformity is severe it is obvious that the evertors and the dorsiflexors are stretched over the convexity of the dorsum and lateral border of the foot, whereas the tibialis anterior and

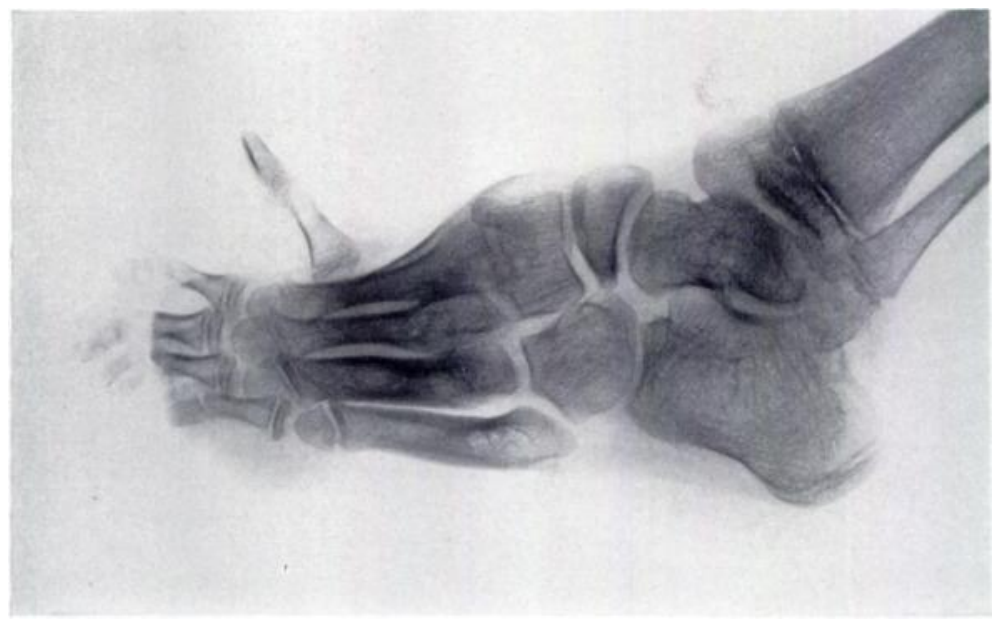

FIG. 1

Radiograph of the deformed foot in a child aged nine years. Well marked bony deformity is present, especially in the navicular and talus. Such a case is unsuitable for the operation described. If transplantation of the tibialis anterior is undertaken it should be done before secondary bone changes have occurred.

tibialis posterior extend in a straight line to their insertion in the concavity of the medial border of the foot. Not only do these muscles act at a great advantage, but the tibialis anterior acts almost as a pure invertor, with little power as a dorsiflexor of the foot. It should be remembered that all tendons, except the tendo calcaneus, are inserted in front of the midtarsal joint, and that the bone least affected in club-foot, namely the talus, receives no muscle attachment except a slip from the tendon of the tibialis posterior. When deformity recurs soon after adequate treatment is stopped, it develops so rapidly that it cannot be attributed to the contraction of fibrous tissue or to an anomaly of bone growth. It has been accepted in other conditions that the most rapidly deforming factor in a limb is muscle imbalance.

vol. $34 \mathrm{~B}$, xo. 1, FEBRCARY 1952 
PRINCIPLE OF THE TIBIALIS ANTERIOR TRANSFER

Examination of patients with relapsed club-foot revealed a relative weakness of the evertors. There may be some correlation between the deformity and the fact that the peronei are the last muscles of the leg to receive their nerve supply (Harris 1942). It is also possible that intra-uterine pressure may damage the common peroneal nerve as it passes round the neck of the fibula, and thus lead to muscle imbalance. If the hypothesis of muscle imbalance is correct, lateral transfer of the insertion of the tibialis anterior tendon, after the deformity

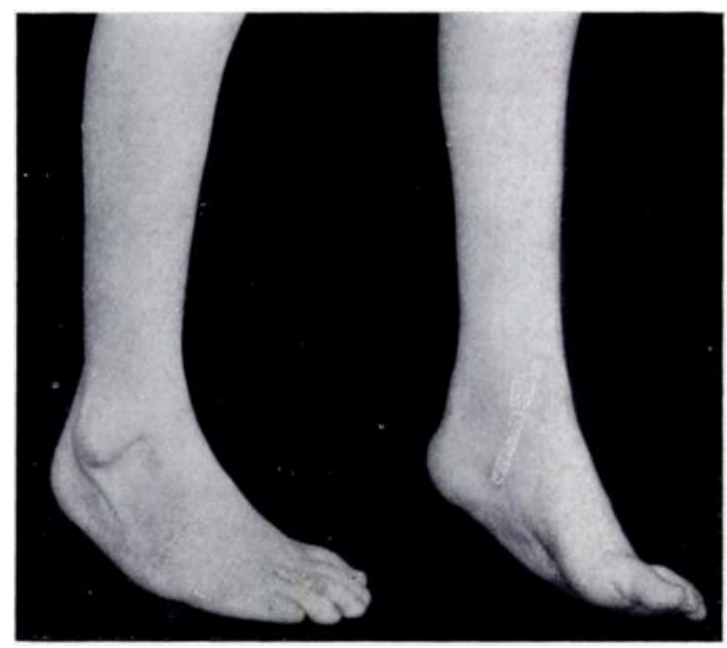

FIG. 2

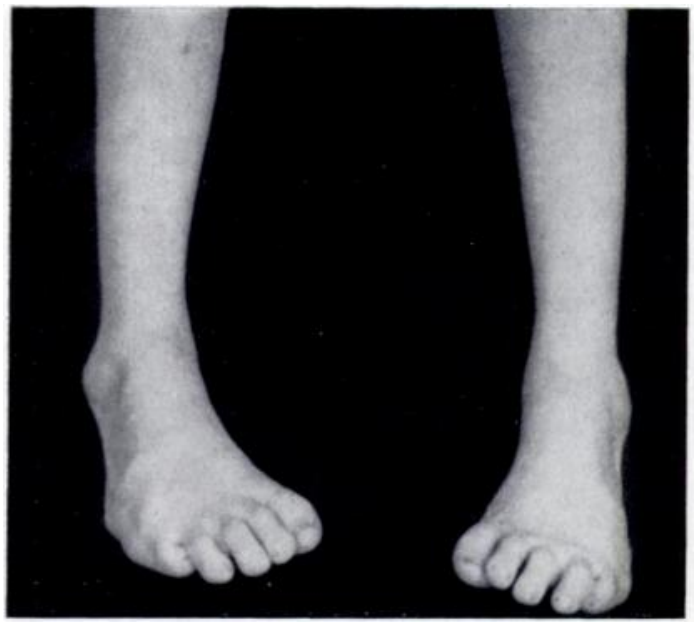

FIG. 3

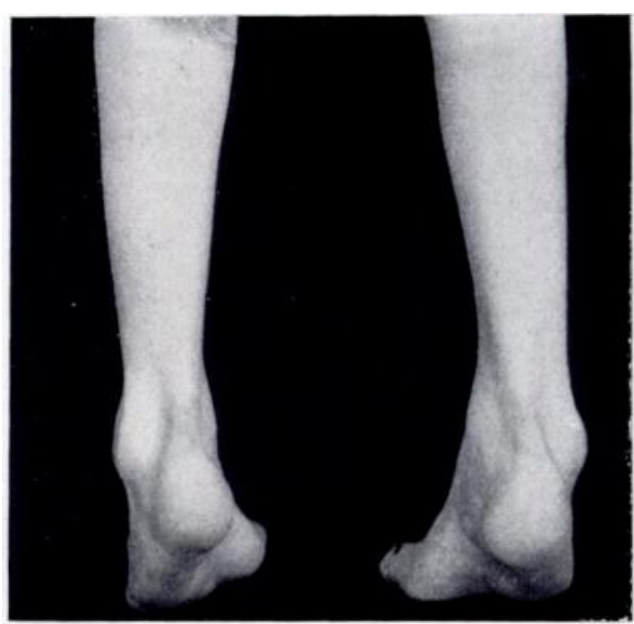

Fig. 4

Case 1. Figures 2 to 4- Typical congenital talipes equinovarus deformity before correction and lateral transplant of tibialis anterior tendon.

has been corrected, should prevent it from recurring, for the transplanted tendon will act as a dorsiflexor and as an evertor. Camera (19.50) believes that transplantation of the tibialis anterior may lead to over-correction of the deformity, and he prefers to attach the two outer tendons of the extensor digitorum longus to the distal third of the fifth metatarsal. While not denying the value of Camera's method, we submit the present review as an indication of the efficacy of tibialis anterior transplants done in this hospital during the last four years. So far there has been no case of over-correction of the deformity after the transplant. 


\section{CLINICAL MATERIAL}

The series includes nineteen patients. Operation was undertaken on both feet in three. making a total of twenty-two tendon transplants. Nine were done in the right foot, and thirteen in the left. Eleven patients were females, and eleven males. The age at the time of operation varied from three to thirteen years, with an average of five and a half years; and the follow-up period varied from six months to four years. Most of our patients had previously had operations such as plantar fasciotomy, or Steindler's operation, or elongation of the tendo calcaneus.

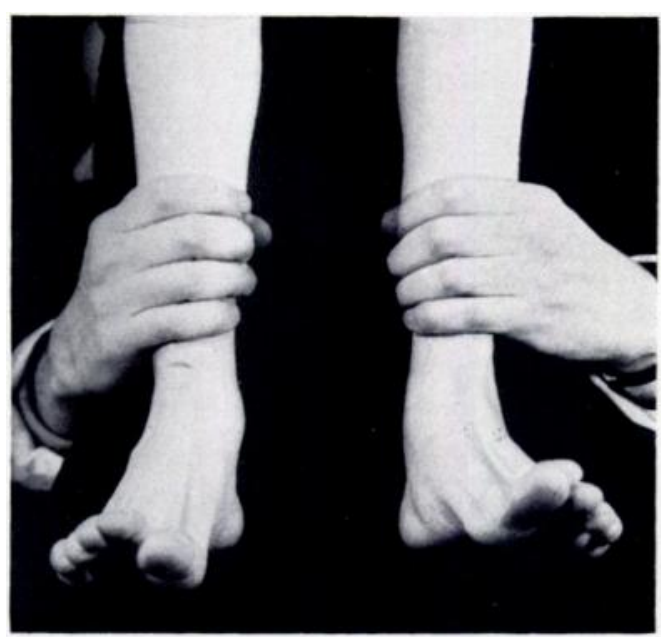

Fig. 5

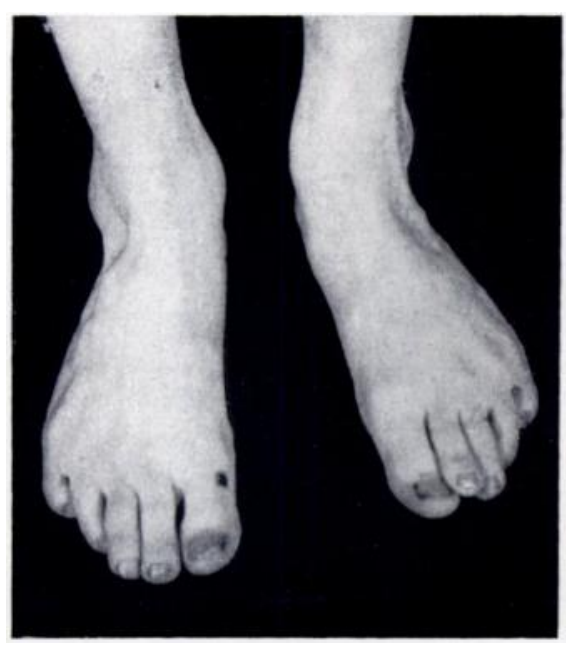

FIG. 6

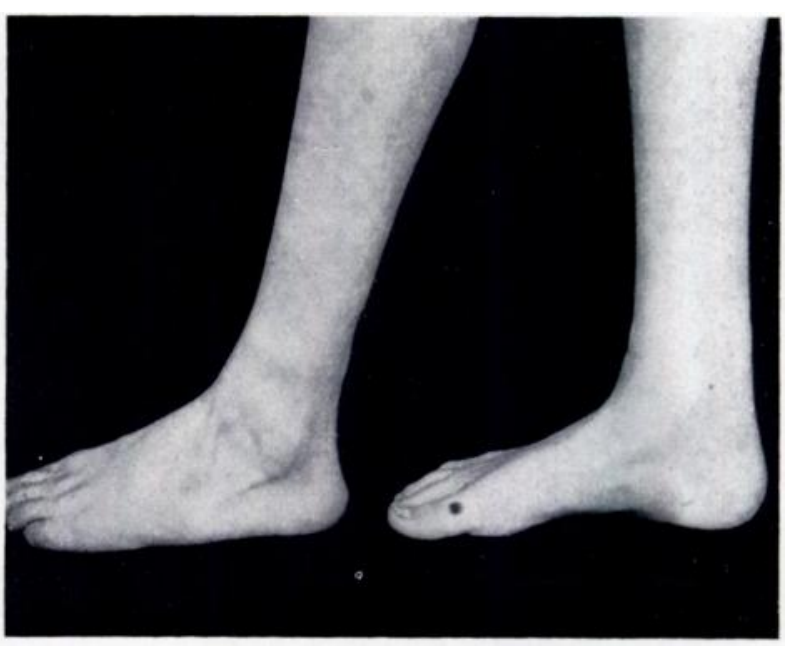

FIG. 7

Case 1. Figures 5 to 7 -Condition four years after operation. showing improved appearance of the feet and active dorsiflexion and eversion.

\section{TECHNIQUE OF OPERATION}

The best age for operation is between three and six years. After the age of six year: secondary changes in the soft tissues and bones prevent adequate correction (Fig. 1 ). It is well known that a tendon transplant will not correct a fixed deformity. For this reason over-correction by manipulation and plaster and if necessary elongation of the tendo calcaneus, with or without posterior capsulotomy of the talo-calcaneal and ankle joints, may be required to over-correct the deformity before transplantation.

VOl. 34 B, No. 1, FEBRUARY 1952 
At operation the tendon of the tibialis anterior is transplanted into the cuboid or, if the tendon is sufficiently long, into the base of the fifth metatarsal bone. An above-knee walking plaster, applied with the foot in the slightly over-corrected position, is worn for six months. After removal of the plaster a course of re-educative exercises is advised.

\section{RESULTS}

Results have been classified as good, fair, and bad. The criteria for a good result were: absence of pain, normal appearance, no limp, plantigrade position, active dorsiflexion and eversion (Figs. 2 to 7 ). These requirements were met in sixteen patients.

The criteria for a fair result were: absence of pain, plantigrade position, no limp and only slight residual deformity. There were two patients in this group.

Four patients have had bad results. Failure was attributed in one patient to rigidity of the feet caused by many previous operations. In another patient the tendon separated from its new insertion. There was persistent deformity in two patients, probably caused by too short a period of post-operative immobilisation.

We have observed that after transplantation of the tibialis anterior the extensor hallucis longus takes over some of the original function of the tibialis anterior: thus, during active dorsiflexion the hallux first hyperextends at the metatarso-phalangeal joint, then the foot dorsiflexes.

\section{SUMMARY AND CONGLUSIONS}

1. Twenty-two cases of transplantation of the tibialis anterior for relapsed club-foot have been reviewed. Results were good in sixteen cases, fair in two and bad in four.

2. The operation and routine treatment are described.

3. The reasons for the four failures are discussed.

4. It is concluded that the operation is well worth while, and will often avoid the need for bony stabilisation at a later date.

We are indebted to the late Mr G. R. Girdlestone, and to Mr W. B. Foley, Mr J. C. Scott and Mr E. W. Somerville for permission to investigate their case records. We wish especially to express our appreciation to Professor Trueta and to $\mathrm{Mr} \mathrm{J}$. C. Scott for their helpful criticisms and valuable assistance in the preparation of this paper.

\section{REFERENCES}

Brockman, E. P. (1930): Congenital Club-foot. Bristol: John Wright \& Sons Ltd.

Brockman, E. P. (1937): Modern Methods of Treatment of Club-foot. British Medical Journal, ii, 572.

Browne, D. (1937): Modern Methods of Treatment of Club-foot. British Medical Journal, ii, 570.

CAMerA, U. (1950): Indivizzi Clinici, mitodi operatori, technicke chirurgeiche originali e personali del Prof. Ugo Camera. Torino, p. 197.

Duns, Nacghtox (1923): The Treatment of Congenital Talipes Equinovarus. British Medical Journal, ii, 1216.

GarceaU, G. J. (1940): Anterior Tibial Tendon Transposition in Recurrent Congenital Club-foot. Journal of Bone and Joint Surgery, 22, 932.

Garceau, G. J., and Manning, K. R. (1947): Transposition of the Anterior Tibial Tendon in the Treatment of Recurrent Congenital Club-foot. Journal of Bone and Joint Surgery, 29, 1044.

HaRris, H. A. (1942): Posture in Industry. Lancet, ii, 56.

Middefon, D. S. (1934): Studies on Pre-natal Lesions of Striated Muscle as Cause of Congenital Deformity. Edinburgh Medical Journal, N.S. 41, 401.

Steinder, A. (1920): Stripping the Os Calcis. Journal of Orthopaedic Surgery, 2, 8. 